\title{
DOES TRADITIONAL MEDICINE USE HAMPER EFFORTS AT TUBERCULOSIS CONTROL IN URBAN PERU?
}

\author{
CLARISSA C. OESER, ADRIAN R. ESCOMBE, ROBERT H. GILMAN, JON S. FRIEDLAND, CARLTON A. W. EVANS, \\ AND DAVID A. J. MOORE* \\ Asociación Benéfica PRISMA, Lima, Peru; Universidad Peruana Cayetano Heredia, Lima, Peru; Department of Infectious Diseases \\ and Wellcome Centre for Clinical Tropical Medicine, Imperial College, London, United Kingdom
}

\begin{abstract}
Decades of social and political unrest have contributed to the urbanization of the population of Peru with large-scale migration from rural Andean and Amazonian communities to overcrowded shantytowns around Lima. We administered a face-to-face survey questionnaire to 116 patients with suspected and proven tuberculosis (TB) in northern Lima to determine the extent to which the use of traditional therapies from indigenous regions persists and the impact of any such use on TB control. Sixty-three percent of participants reported some form of self-treatment prior to presentation to the National Tuberculosis Program; 52\% of them used traditional remedies. Symptom duration was longer among self-remedy users than non-users (median $=25$ versus 15 days; $P=0.07$ ) and among those exclusively using western remedies rather than traditional remedies (median $=30$ versus 15 days; $P=0.01$ ). We thus found no evidence that use of traditional remedies has an appreciable effect on diagnostic delay in Lima.
\end{abstract}

\section{INTRODUCTION}

Tuberculosis (TB) is primarily a disease of poverty and the vast majority of the global burden of disease is to be found in resource-poor settings. Although the National Tuberculosis Control Program of Peru has demonstrated some early success in reducing the incidence of new TB cases through the application of the World Health Organization directly observed therapy, short course (DOTS) strategy, ${ }^{1}$ Peru remains the country in Latin America (after Brazil) with the second highest burden of TB and until recently was included among the top 22 highest burden countries globally (which are together responsible for $80 \%$ of the TB in the world). ${ }^{2}$

Transmission of TB is facilitated by overcrowding and poverty; thus, the population distribution of this disease is uneven. Although the nationwide incidence of smear-positive TB in Peru was 134 cases per 100,000 population in 2000, the incidence in Lima and Callao (the port province adjacent to Lima) was 242/100,000/year, ${ }^{3}$ and periurban shantytowns have previously been shown to be zones of TB hyperendemicity. ${ }^{4}$ Overcrowding in Lima, as in most cities in the developing world, is directly related to increasing urbanization.

The political and security climate of the last three decades in Peru has resulted in marked demographic changes, with the population of Lima having increased by more than $290 \%$ from an estimated 2.1 million in the 1960 s to 6.5 million in 1994. The population in 2005 is now widely regarded as exceeding nine million people. Economic migrants and internally displaced populations fleeing the terrorist activities of Sendero Luminoso (Shining Path) and Tupac Amaru Revolutionary Movement (MRTA) guerrillas have resulted in a large migrant influx to Lima of traditionally rural populations from the high sierra of the Andes and the tropical rainforest of the Amazon Basin. ${ }^{6}$ These communities usually maintain strong cultural and family ties with their origins, ${ }^{7}$ and traditional beliefs and practices often persist widely. ${ }^{8-10}$ Many of the source communities for these people remain culturally

\footnotetext{
* Address correspondence to David A. J. Moore, Universidad Peruana Cayetano Heredia, Avenida Honorio Delgado No. 430, Urb, Ingenieria, San Martin de Porras, Lima 31, Peru and Wellcome Centre for Clinical Tropical Medicine, Imperail College, London, United Kingdom. E-mail: daj.moore@imperial.ac.uk
}

and geographically isolated, and the use of traditional remedies in these communities is widespread. ${ }^{11}$

The success of the National TB Control Program (NTP) is dependent upon potential TB cases submitting sputum samples to health clinics for TB diagnosis. Earlier diagnosis reduces ongoing transmission and reduces community-wide disease burden. It is not known whether presentation for diagnostic testing is delayed by health care-seeking behaviors that divert suspected case of TB into other diagnostic and therapeutic arenas (either traditional or western biomedical treatment) from the NTP, or whether any such delays are of sufficient magnitude to hamper NTP efforts at TB control by lengthening pre-treatment duration of infectivity and ongoing transmission.

We hypothesized that traditional beliefs prevalent in rural to urban migrant communities in Lima would lead suspected cases of TB to seek diagnostic and therapeutic assistance from outside the NTP, and that this would result in significant delays in the initiation of effective chemotherapy, which would perpetuate avoidable, ongoing transmission of TB. We further hypothesized that this situation might demand an intervention based around collaboration and formal engagement of the NTP with traditional practitioners to enhance TB control.

\section{MATERIALS AND METHODS}

Setting. This work was conducted over a three-month period (April-June 2004) as a sub-study nested within an ongoing operational evaluation of a novel TB diagnostic test being conducted in collaboration with the NTP in 10 health centers in northern Lima. In this evaluation, all suspected cases of TB attending the NTP at a health center for investigation were invited to participate in the study, which involves agreeing to further tests being performed on their routine sputum sample and answering a clinical questionnaire in a face-to-face interview with a study nurse or physician.

Study population. Patients were recruited in two ways: 1) study participants previously enrolled in the parent study who were diagnosed with $\mathrm{TB}$ and receiving treatment were invited to participate; 2) suspected cases of TB were invited to participate at the moment of enrollment into the parent study (many of whom it was assumed would turn out not to have TB). 
Questionnaire. A semi-structured questionnaire was administered in a face-to-face interview with the study nurse or physician. Three interviewers conducted joint interviews together during the pilot and initial phase of the study to establish a common consensus on data collection. Information was collected about prior use and source of traditional or western biomedical remedies in the current and previous illnesses, symptom spectrum and duration, duration of remedy use, knowledge and understanding of TB, and standard demographic indices. Responses were recorded both by selection of options from a list and from freely volunteered observations and comments.

Definitions. Patients with TB were diagnosed in the parent study by sputum culture; thus, all TB patients had microbiologically confirmed disease. Suspected cases of TB were defined as any subject coming to a health center for investigation of TB. The NTP invites all subjects with a cough of $>15$ days duration to present for testing. Diagnostic delay in this study was regarded as a symptom period prior to presentation extending beyond 21 days. Alternative remedies were defined as either traditional methods (consultation with or remedy provided by curanderos [traditional healers in Peru], specialists in natural medicine, vendors of herbs or potions at markets, or the use of herbal remedies, whether self prescribed or taken on the advice of family or friends) and western type (biomedical methods, medication provided by pharmacists, private doctors, or hospitals).

Data analysis. Data was entered into a Microsoft (Redmond, WA) Excel ${ }^{\circledR}$ spreadsheet and statistical analysis was performed using Stata 7.0 (Stata Corp., College Station, TX).

Ethical approval. The protocol for the parent study, which included questionnaire administration, and the informed consent forms signed by all participants were reviewed and approved by the institutional review boards of Universidad Peruana Cayetano Heredia (Lima, Peru), the Asociación Benéfica PRISMA (Lima, Peru), Johns Hopkins Bloomberg School of Public Health (Baltimore, MD), and Imperial College (London, United Kingdom).

\section{RESULTS}

Overall study population. The mean age of the 116 study participants was 33 years and 55\% were female. Forty-three
(37\%) were recruited at the time of presentation (suspected cases of TB) and $73(63 \%)$ were recruited while already receiving treatment for TB (TB patients). Twelve (28\%) of the suspected cases of TB were subsequently found to have culture-positive TB (for the purposes of this analysis, they have been classified as suspected cases of TB because their responses at the interview were those of suspected cases of TB awaiting diagnosis. There were no differences in the demographic characteristics of suspects cases of TB and the TB patients (Table 1). Analyses were performed on the whole study population except for the investigation of disease knowledge and understanding, for which TB patients (who receive education at the time of diagnosis and during treatment) and suspected cases of TB were analyzed separately.

Use of remedies prior to current presentation to the NTP. Seventy-three (63\%) participants reported use of alternative remedies prior to presentation for investigation at a health center. Of these, 22 (19\% of all participants) reported exclusively traditional remedy use, 34 (29\%) reported exclusive use of western products, and 17 (15\%) reported using both categories (Figure 1). The demographics of each group (users and non-users, and traditional remedy and western remedy users) are shown in Table 1.

Self-treatment with traditional and western remedies was initiated after an average symptom duration of 19 and 31 days, respectively, with $50 \%$ and $67 \%$ of therapies initiated after 21 days (the point beyond which presentation for TB diagnosis is regarded as delayed). Traditional medicines were used for a median of 5 days and western medicines were used for a median of 10 days.

The sources of advice and actual remedies of all users were most commonly pharmacies $(49 \%)$, or the advice of family or friends or self prescription (42\%). A private physician had been consulted by $19 \%$ and a market vendor of herbal remedies by $11 \%$, while $4 \%$ had previously self-presented to a hospital and only $1 \%$ each chose the advice of a curandero or a specialist in natural medicine. Traditional remedies used for this and previous clinical episodes are shown in Table 2. Western biomedical remedies used were most commonly antibiotics (amoxicillin, penicillin, cotrimoxazole, ciprofloxacin), anti-inflammatory drugs, anti-tussives, bronchodilators, or vitamins. Antituberculosis drugs are not available over the counter in Peru.

TABLE 1

Demographics of study participants

\begin{tabular}{|c|c|c|c|c|c|c|c|c|c|}
\hline \multirow[b]{2}{*}{ Parameter } & \multicolumn{2}{|c|}{$\begin{array}{c}\text { All subjects } \\
(\mathrm{n}=116)\end{array}$} & \multicolumn{2}{|c|}{$\begin{array}{l}\text { All subjects } \\
(\mathrm{n}=116)\end{array}$} & \multicolumn{2}{|c|}{$\begin{array}{l}\text { All users } \\
(\mathrm{n}=73)\end{array}$} & \multicolumn{2}{|c|}{$\begin{array}{l}\text { All subjects } \\
(\mathrm{n}=116)\end{array}$} & \multirow[b]{2}{*}{$\begin{array}{c}\begin{array}{c}\text { Total } \\
(\mathrm{n}=116\end{array}\end{array}$} \\
\hline & $\begin{array}{c}\text { TB } \\
\text { patients }\end{array}$ & $\begin{array}{c}\mathrm{TB} \\
\text { suspects }\end{array}$ & Nonusers & Users & Traditional* & Western* & No delay & Delay & \\
\hline Number & 73 & 43 & 43 & 73 & 39 & 51 & 60 & 56 & 116 \\
\hline Proportion in each subgroup (\%) & 63 & 37 & 37 & 63 & $52 \dagger$ & $69 \dagger$ & 52 & 48 & 100 \\
\hline Age in years (mean) & 32 & 35 & 32 & 34 & 35 & 33 & 31 & 35 & 33 \\
\hline Proportion female $(\%)$ & 55 & 56 & 53 & 56 & 63 & 59 & 53 & 43 & 55 \\
\hline Provincial migrants to Lima (\%) & 55 & 56 & 60 & 49 & 50 & 45 & 50 & 50 & 55 \\
\hline Mean duration lived in Lima (years) & 16 & 16 & 15 & 17 & 16 & 17 & 15 & 18 & 16 \\
\hline Provincial parental origin (\%) & 97 & 100 & 93 & 97 & 98 & 98 & 92 & 100 & 96 \\
\hline Median symptom duration (days) & 21 & 20 & 15 & 25 & 20 丰 & $30 \ddagger$ & 14 & 30 & 20 \\
\hline Education level (\% secondary) & 84 & 81 & 86 & 81 & 79 & 84 & $90 \S$ & $75 \S$ & 83 \\
\hline
\end{tabular}

17 subjects used both traditional and western remedies and thus are listed in both columns.

T Percentages refer to the proportion of self-medicators who used each type of remedy.

$\ddagger$ Median symptom duration includes subjects using both western and traditional remedies in addition to exlusive users of one type; thus, figures differ from the text, which refers to exclusive users alone.

$\S P=0.03$, by chi-square test. 

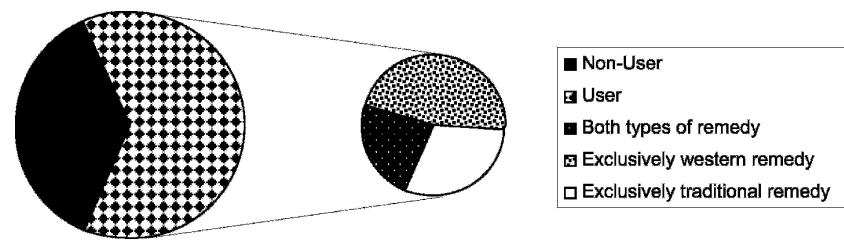

FIGURE 1. Use of remedies prior to presentation to the National Tuberculosis Control Program $(\mathrm{n}=116)$.

General health-seeking behavior and use of traditional medicine prior to current illness episode. Fifty-six percent of participants $(n=65)$ reported previous use of traditional medicine for other illnesses. Of these, only $4 \%$ had visited a curandero, $5 \%$ reported seeking advice from a natural medicine specialist, $16 \%$ bought herbal remedies from market vendors, and $44 \%$ had used traditional medication either self prescribed or on the advice of family or friends. The mean duration of therapy was 14 days and most participants had obtained their traditional remedies in Lima. Traditional medicines had been used for respiratory infections $(\mathrm{n}=33)$, influenza $(\mathrm{n}=7)$, abdominal pain $(\mathrm{n}=7)$, prior TB $(\mathrm{n}=5)$, gastritis $(\mathrm{n}=3)$, anxiety and stress $(\mathrm{n}=3)$, gallstones $(\mathrm{n}=$ $3)$, anemia $(n=2)$, and assorted renal and hepatic disorders, scleroderma, anorexia, arthritis, intoxication, asthma, diabetes, and headaches. The most commonly reported traditional remedies used in previous illness episodes are shown in Table 2. Other traditional therapies used only occasionally included cleansing with a guinea pig, embalming with snake cartilage or grease, and the consumption of quail lung, mashed toad extract, or extract of the trunk of banana shrubs.

TABLE 2

Traditional remedies used for self-treatment in current and prior illnesses (in descending order of overall reported frequency)

\begin{tabular}{|c|c|c|c|}
\hline Local name & $\begin{array}{l}\text { Scientific name } \\
\text { (where relevant) }\end{array}$ & $\begin{array}{l}\text { Use in } \\
\text { current } \\
\text { illness }\end{array}$ & $\begin{array}{l}\text { Use in } \\
\text { prior } \\
\text { illness }\end{array}$ \\
\hline Eucalyptus & & $\checkmark$ & $\checkmark$ \\
\hline Huamanripa & Senecio tephrosidioides & $\checkmark$ & $\checkmark$ \\
\hline Lime with honey & & $\checkmark$ & $\checkmark$ \\
\hline $\begin{array}{l}\text { Unspecified herbal } \\
\text { mixture }\end{array}$ & & $\checkmark$ & $\checkmark$ \\
\hline Garlic and onions & & $\checkmark$ & $\checkmark$ \\
\hline Camomile & & $\checkmark$ & $\checkmark$ \\
\hline Maca & Lepidium peruvianus & & $\checkmark$ \\
\hline Savila & Aloe vera & $\checkmark$ & $\checkmark$ \\
\hline Alfalfa extract & Medicago sativa & $\checkmark$ & $\checkmark$ \\
\hline Escorzonera & Scorzonera hispanico & $\checkmark$ & \\
\hline Romero & Rosmarinus officinalis $L$. & $\checkmark$ & \\
\hline Beterraga & Beta vulgaris L. & $\checkmark$ & \\
\hline Muña & Minthostachys mollis & & $\checkmark$ \\
\hline Valeriana & Valeriana ceratophylla & & $\checkmark$ \\
\hline Uña de gato & Uncario tomentosa & & $\checkmark$ \\
\hline Oregano & & & $\checkmark$ \\
\hline Cola de Caballo & Equisetum sp. & & $\checkmark$ \\
\hline Berro & Nasturtium officinalis & & $\checkmark$ \\
\hline Flor blanca & Plumeria sp. & & $\checkmark$ \\
\hline Apio & Apium graveolens & & $\checkmark$ \\
\hline Tara & Lycopersicon lycopersicum & & $\checkmark$ \\
\hline Nogal & Juglandaceae juglans & & $\checkmark$ \\
\hline Cedron & Simaba cedron simarubaceae & & $\checkmark$ \\
\hline Santa Maria Marcos & Balsamita tanacetum & & $\checkmark$ \\
\hline Ajonjolí & Sesamum indicum $L$. & & $\checkmark$ \\
\hline
\end{tabular}

Diagnostic delay. Median overall symptom duration prior to presentation to the NTP was 20 days with presentation to the health center delayed (> 21 days of symptoms) in 56 $(48 \%)$ of all subjects. The demographics of subjects with delayed and timely presentation (within 21 days) are shown in Table 1. Of all the indices recorded, only a lower level of educational attainment was associated with delay in presentation $(P=0.03$, by chi-square test).

Self-medication users were more likely to have a delayed presentation than non-users (median symptom duration $=25$ versus 15 days; $P=0.07$, by Wilcoxon rank sum test), and the presentation of exclusive users of western remedies was significantly more delayed than that of exclusive users of traditional remedies (median $=30$ versus 15 days; $P=0.01$, by Wilcoxon rank sum test).

Self-reported reasons for delayed presentation $(\mathrm{n}=56)$ included a perception that the symptoms would self resolve $(66 \%)$, a lack of time to attend $(30 \%)$, that the investigation (which is free at point of care) would be costly (14\%), and a general aversion to physicians and western medicine (10\%).

Although contrary to NTP guidelines (which require sputum examination after 15 days of cough) $27 \%$ (31 of 116) of subjects came to health centers within 14 days of symptom onset and were investigated for TB. Twenty-one (68\%) of these 31 early presenters had culture-proven TB.

Understanding and beliefs about tuberculosis. Seventyseven percent of TB patients and 37\% of suspected cases of $\mathrm{TB}$ had received TB education in some form. The suspected cases of $\mathrm{TB}$ and $\mathrm{TB}$ patients were in general reasonably well-informed about the cause of $\mathrm{TB}$, mechanisms of transmission, treatment strategies, and likelihood of cure. Fewer than $2 \%$ invoked religion or curses as causal and more than $96 \%$ recognized the importance of contact with a person with TB. Seventy-two percent recognized the importance of airborne spread and the association of cough with transmissibility, but $51 \%$ thought that sharing cutlery could lead to transmission. Thirty percent believed that air contamination was relevant, $28 \%$ that alcohol and/or smoking were contributory, and $38 \%$ that germs were to blame for development of disease.

Almost all participants understood that TB was curable and $19 \%, 32 \%$, and $34 \%$ believed that good behavior with or without prayer, relaxation/rest/sleep, and cessation of smoking or drinking were important factors for recovery. More than $90 \%$ recognized the key importance of TB therapy. There were strong beliefs in the importance of nutrition in the contracting of and curing of TB.

Although only $50 \%$ of users of traditional remedies had received TB education compared with $69 \%$ of western remedy users, the knowledge and beliefs of users of traditional medicines did not differ from those reporting use of western remedies (and the proportion of TB patients was equal in both groups).

\section{DISCUSSION}

The key findings of this study are that two-thirds of subjects sought alternative health care prior to presentation to the NTP and that one-third used traditional medicines. However, while the association with diagnostic delay from traditional medicine use is negligible, the use of western medicines is associated with greater prolongation of symptom duration 
prior to presentation to the NTP. This is due, in part, to later initiation of self therapy and, in part, because the treatment duration is twice as long when compared with traditional remedy use. An important observation in this study was that the overall median symptom duration of 20 days is relatively short. This suggests that this urban population is both aware of the significance of prolonged cough and other potential TB symptoms and of the diagnostic facility provided by the NTP. Moreover, of the $27 \%$ of subjects who (strictly speaking) incorrectly presented for TB investigation prior to the 15-day symptom duration recommended by the NTP, more than twothirds were found to have TB, suggesting that review of current guidelines might be warranted.

These findings contrast with similar studies from Africa and Asia. Such differences might be attributable to traditional beliefs being held more strongly elsewhere ${ }^{12}$ or a more influential role of traditional healers in primary health care. ${ }^{13} \mathrm{Al}$ ternatively, there may be greater community understanding and knowledge of TB transmission, symptoms, and treatment in Peru. ${ }^{14}$ The impact of TB-associated stigma may also vary between settings with avoidance of engagement with the NTP a strategy to conceal a diagnosis perceived as shameful. ${ }^{13,15}$ In such a situation, a visit to the traditional healer is less overtly linked to TB, particularly if access to the NTP is difficult or obvious. ${ }^{16}$ Perhaps surprisingly, in our study population only three $(2.5 \%)$ subjects with a delayed presentation cited a concern about being publicly suspected of having TB or another serious disease as a reason for the delay In contrast with African settings, infection with human immunodeficiency virus is uncommon in Peru (population prevalence $<0.5 \%$ ); thus, the association with this other stigmatized disease is not made.

Many of the traditional remedies used by our study population mirror those used by people in industrialized nations, where there has been an explosion in the popularity of alternative therapies, particularly herbal medicine and functional food, which are used more often as complementary than as an alternative to conventional biomedicine. ${ }^{17}$

The potentially important role of traditional medicine in public health has been recognized by international health organizations such as the World Health Organization and the Pan American Health Organization, which since 1977 have promoted policies aimed at exploring mechanisms to coordinate this sector with governmental health systems focused mainly on primary health care. ${ }^{18}$ Peru has a strong tradition of folk medicine, dating back more than 3,000 years. Traditional healers, curanderos (in Spanish, curar $=$ to heal) assume a primary role in health care in remote areas and often represent the only regular access to a health care practitioner. In shamanic culture, they are considered both priests and therapists, being knowledgeable about all healing plants and rites. ${ }^{11,19}$ The principal traditional medical specialities are herbalism (Hierberas), bone setting (folk chiropracticer, Sobador), and traditional birth attendance (Partera). Traditional medicine use has been noted all over Peru and among all social classes. ${ }^{20}$ It was interesting to note in our study that neither age, sex, nor geographic origin significantly determined health-seeking behavior. Although billboards advertising the services of curanderos to resolve marital problems are common in Lima, it appears from our data that consultation with curanderos for conventional medical symptoms, such as the persistent cough of $\mathrm{TB}$, is uncommon in this urban population. The median duration of residence in Lima in our study population was 16 years and it is conceivable that in more recently arrived groups there is greater reliance on traditional remedies. However, we found no evidence that likelihood of any remedy use or traditional rather than western remedy use was associated with duration of Lima residence within our study group (range $=0.2-50$ years).

We conclude from this study that traditional medicine does not contribute through diagnostic delay in any important negative way to the high incidence of $\mathrm{TB}$ in Lima shanty towns. However, it is important to note that only a population-based study could provide more definitive evidence since it is conceivable that some patients may remain in the community using traditional therapies without ever coming to the attention of the NTP. Based on this evidence, it does not appear that educational interventions aimed at traditional medicine or collaboration with traditional healers currently warrant prioritization of scant TB control resources in this setting. Although relatively minor, the delay in presentation arising from western remedy use and the magnitude of the frequency of such delay warrants further investigation of whether educational interventions targeted at pharmacy staff and their customers can reduce diagnostic delay among suspected cases of TB.

Received February 21, 2005. Accepted for publication March 7, 2005.

Acknowledgments: We thank all participants in this study and Fanny García, Rosmery Gutierrez, Sonia Lopez, Carolay Salas, Eleana Sanchez, and Christian Solis for their crucial assistance with field work.

Financial support: Clarissa C. Oeser was supported by the Johns Hopkins/Weizmann Institute Research Exchange Program. Adrian R. Escombe, Carlton A. W. Evans, and David A. J. Moore were supported by Wellcome Trust Research Fellowships in Clinical Tropical Medicine.

Authors' addresses: Clarissa C. Oeser, Adrian R. Escombe, and Robert H. Gilman, Asociación Benéfica PRISMA, Carlos Gonzales No. 251, Urb. Maranga, Lima 32, Peru, Telephone: 51-1-464-0221, Fax: 51-1-464-0781. Jon S. Friedland, Wellcome Centre for Clinical Tropical Medicine, Imperial College London (Hammersmith Campus), DuCane Road, London W12 0NN, United Kingdom, Telephone: 44208-383-1943, Fax: 44-208-383-3394. Carlton A. W. Evans, Universidad Peruana Cayetano Heredia, Avenida Honorio Delgado No. 430, Urb, Ingenieria, San Martin de Porras, Lima 31, Peru, Telephone: 51-1-382-0929, Fax: 51-1-464-0781. David A. J. Moore, Universidad Peruana Cayetano Heredia, Avenida Honorio Delgado No. 430, Urb, Ingenieria, San Martin de Porras, Lima 31, Peru and Wellcome Centre for Clinical Tropical Medicine, Imperial College, London W12 0NN, United Kingdom, Telephone: 51-1-382-3398, Fax: 51-1-464-0781; E-mail: daj.moore@imperial.ac.uk.

\section{REFERENCES}

1. Suarez PG, Watt CJ, Alarcon E, Portocarrero J, Zavala D, Canales R, Luelmo F, Espinal MA, Dye C, 2001. The dynamics of tuberculosis in response to 10 years of intensive control effort in Peru. $J$ Infect Dis 184: 473-478.

2. WHO, 2001. WHO Report 2001 Global TB Control. Geneva: World Health Organization.

3. Tuberculosis en el Perú, Informe, 2000. Lima: Dirección General de Salud de las Personas, Ministerio de Salud.

4. Sanghavi DM, Gilman RH, Lescano-Guevara AG, Checkley W, Cabrera LZ, Cardenas V, 1998. Hyperendemic pulmonary tuberculosis in a Peruvian shantytown. Am J Epidemiol 148: 384-389. 
5. Población Total Proyectada al 30 de Junio de 1994, 1994. Lima: Instituto Nacional Estadística.

6. Peru, estimaciones y proyecciones de población 1950-2050, 2001. Boletín de Análisis Demográfico: Dirección Técnica de Demografía e Indicadores Sociales. Lima, Peru: Instituto Nacional de Estadística e Informática.

7. Hudson RA, 1993. Peru: A Country Study: Washington, DC: Defense Department, U.S. Army.

8. Escobar GJ, Salazar E, Chuy M, 1983. Beliefs regarding the etiology and treatment of infantile diarrhea in Lima, Peru. Soc Sci Med 17: 1257-1269.

9. Davidson J, 1983. The survival of traditional medicine in a Peruvian barriada. Soc Sci Med 17: 1271-1280.

10. Roemer MI, 1986. The changeability of health care systems. Latin American experience. Med Care 24: 24-29.

11. de Feo V, 2003. Ethnomedical field study in northern Peruvian Andes with particular reference to divination practices. $J$ Ethnopharmacol 85: 243-256.

12. Eastwood SV, Hill PC, 2004. A gender-focused qualitative study of barriers to accessing tuberculosis treatment in The Gambia, west Africa. Int J Tuberc Lung Dis 8: 70-75.

13. Edginton ME, Sekatane CS, Goldstein SJ, 2002. Patients' beliefs: do they affect tuberculosis control? A study in a rural district of South Africa. Int J Tuberc Lung Dis 6: 1075-1082.
14. Wandwalo ER, Morkve O, 2000. Knowledge of disease and treatment among tuberculosis patients in Mwanza, Tanzania. Int $J$ Tuberc Lung Dis 4: 1041-1046.

15. Johansson E, Long NH, Diwan VK, Winkvist A, 2000. Gender and tuberculosis control: perspectives on health seeking behaviour among men and women in Vietnam. Health Policy 52: 33-51.

16. Lienhardt C, Rowley J, Manneh K, Lahai G, Needham D, Milligan P, McAdam KP, 2001. Factors affecting time delay to treatment in a tuberculosis control programme in a subSaharan African country: the experience of The Gambia. Int $J$ Tuberc Lung Dis 5: 233-239.

17. Barnes PM, Powell-Griner E, McFann K, Nahin RL, 2004. Complementary and alternative medicine use among adults: United States, 2002. Adv Data (343): 1-19.

18. Nigenda G, Mora-Flores G, Aldama-Lopez S, Orozco-Nunez E, 2001. Practice of traditional medicine in Latin America and the Caribbean: the dilemma between regulation and tolerance. $\mathrm{Sa}$ lud Publica Mex 43: 41-51.

19. Miranda JJ, Nunez H, Alca A, 2002. Traditional healers, still part of the community health systems in the Andes. J Epidemiol Community Health 56: 733.

20. Giese C, 1989. "Curanderos" Traditionelle Heiler in Nord Peru: Muenchner Beitraege zur Amerikanistik. Hoehenschaftlarn, Germany: Klaus Renner Verlag. 